\title{
Thermodynamic Analysis of the Performance of a Single-Effect Absorption Refrigeration System Using the Ammonia/Sodium Thiocyanate Couple
}

\author{
Roméo Gilbert Ngock*, Jean Gaston Tamba, Salomé Ndjakomo, Francis Djanna, Max Ndame \\ Laboratory of Technologies and Applied Sciences, University Institute of Technology, the University of Douala, \\ Douala, Cameroon \\ Email: *romgock@yahoo.fr
}

How to cite this paper: Ngock, R.G., Tamba, J.G., Ndjakomo, S., Djanna, F. and Ndame, M. (2020) Thermodynamic Analysis of the Performance of a Single-Effect Absorption Refrigeration System Using the Ammonia/Sodium Thiocyanate Couple. Open Journal of Energy Efficiency, 9, 53-63.

https://doi.org/10.4236/ojee.2020.91004

Received: February 12, 2020

Accepted: March 20, 2020

Published: March 23, 2020

Copyright $\odot 2020$ by author(s) and Scientific Research Publishing Inc. This work is licensed under the Creative Commons Attribution International License (CC BY 4.0).

http://creativecommons.org/licenses/by/4.0/

\section{(c) (i) Open Access}

\begin{abstract}
This paper aims at presenting analysis of the thermodynamic of the performance of an absorption refrigeration system of the single-effect ammonia/sodium thiocyanate couple. Since the generator is the starting point for the operation of system, one of the most important point to be addressed in this work is to determine the generator's temperatures at which the system can accept the best quantities and qualities of energy. A mathematical model has been developed to study the performance of the system. Equations obtained from the thermodynamic properties of the ammonia/sodium thiocyanate couple were implemented in Matlab. The analysis consists of determining the effects of the generator's temperature on the energy performance of the system. The computerized performance parameters are the coefficient of performance and the energy efficiency. Results indicate that the coefficient of performance increases with the temperature of the generator. Moreover, these remarks are not observed on the exergetic efficiency, because the latter increases until its maximum value 0.43 , in order to decrease until its final value 0.35 . In addition, the maximum value of the coefficient of performance tends towards 0.7 with increasing generator temperature. The system admits better operation when the generator temperatures are between $80^{\circ} \mathrm{C}$ and $90^{\circ} \mathrm{C}$. The determination of this temperature interval by simulation can be use as a variable setting point in controlling the real system.
\end{abstract}

\section{Keywords}

Energy, Exergy, Ammonia/Sodium Thiocyanate, Single Effect 


\section{Introduction}

As time moves, absorption refrigeration systems are becoming more and more attractive because of their compliance with environmental standards. In addition, the waste heat from these systems can be used to provide part of the domestic hot water needs, to heat buildings and to dry food products [1].

Research on the analysis of single-effect absorption refrigeration systems includes the work of Sun [2], which has shown that choosing either $\mathrm{NH}_{3}-\mathrm{LiNO}_{3}$ or $\mathrm{NH}_{3}-\mathrm{NaSCN}$ over $\mathrm{NH}_{3}-\mathrm{H}_{2} \mathrm{O}$ improves the COP of a single-effect absorption refrigeration system, with a recuperative heat exchanger.

Talbi et al. [3] performed an exergy analysis of a single-effect absorption refrigeration machine, using the $\mathrm{NH}_{3}-\mathrm{LiBr}$ torque, to determine the exertion lost in each component, and thus the overall exertion lost by the system. The results reveal that the absorber has the highest energy loss of $15.498 \mathrm{kj} / \mathrm{kg}$. This loss is caused by the temperature difference between the absorber and the environment. The second component of energy loss is the generator, with a loss of $7.0900 \mathrm{kj} / \mathrm{kg}$. This loss is due to the temperature difference between the source and the refrigerant. The third component is the evaporator; a loss caused by the temperature difference between the evaporation temperature and the environment temperature. These three losses can respectively be reduced by increasing the surface area of the absorber, which is a consequence of the high cost of the absorber, by taking all measures to eliminate losses between the heat and the fluids involved. On the other hand, the irreversibilities produced at the level of the evaporator are those that cannot be demonstrated.

$\mathrm{Zhu}$ and $\mathrm{Gu}$ [4] conducted a performance analysis of the absorption system using $\mathrm{NH}_{3}$ as refrigerant and $\mathrm{NaSCN}$ as absorbent. This study determined the COP and efficiency in refrigeration mode and then in heating mode. In addition, the lost exertion in each room and the total lost exertion for each operation (cooling and heating) were calculated. In the case of the refrigerating machine, the result is that the refrigeration COP evolves in the generator and in the evaporation and then decreases in the condenser and the absorber. On the other hand, these remarks are not similar to the cooling exergy efficiency.

Ceroso et al. [5] studied the recuperative heat exchanger of a single-effect absorption machine. This study had shown that the binary pairs $\mathrm{NH}_{3}-\mathrm{LiNO}_{3}$ and $\mathrm{NH}_{3}-\mathrm{NaSCN}$ have the best temperature and viscosity profiles compared to the $\mathrm{NH}_{3}-\mathrm{H}_{2} \mathrm{O}$ pair.

Acuna et al. [6] carried out an energy analysis of a diffusion absorption machine. The aim of this study was to determine the best COP obtained from three solvents $\mathrm{LiNO}_{3} ; \mathrm{NaCSN} ; \mathrm{H}_{2} \mathrm{O}$ and using $\mathrm{NH}_{3}$ as refrigerant, and $\mathrm{H}_{2}$ as inert gas. This study shows that, the combinations formed from the solvents $\mathrm{LiNO}_{3}$ and $\mathrm{NaCSN}$ have a better COP.

In 2014, Sunyoung and Boulama [7] developed a simulation platform, based on advanced exergy analysis, for a single-effect absorption system. The results obtained confirm that the generator and the absorber have more energy loss compared to the evaporator and the condenser. 
In 2016, Xu et al. [8] showed the influence of temperature on COP and mass flow rate in single-effect absorption refrigeration cycles.

An interesting experimental analysis to determine the COP of a single-effect absorption machine was performed by Cai et al. [9]. They concluded that, as the temperature of the generator increases with time, the pressure in the evaporator increases as time progresses.

\section{Methodology and Data}

In this part, we will write the equations for the operation of the system and then develop a simulation model, which will enable us to obtain the results from the described input data. In this view, we will start by describing the functioning of our system.

\subsection{System Description}

Figure 1 shows the various components of the system under study. The high pressure liquid refrigerant (2) coming from the condenser passes into the evaporator at low pressure, after undergoing a pressure drop, through the refrigerant expansion valve. The liquid ammonia evaporates, absorbing heat from the medium to be refrigerated. This ammonia vapour (4) passes into the absorber, where it is absorbed by the lean solution (10) from the generator through a heat exchanger and then forms a rich solution in the absorber. The rich solution is pumped through the heat exchanger and enters the generator to be heated, undergoing desorption. The lean solution obtained by desorption at high pressure (8) returns to the absorber at low pressure through the solution expansion valve. The ammonia vapour obtained by desorption (1), goes into the condenser, liquefying and the cycle starts again.

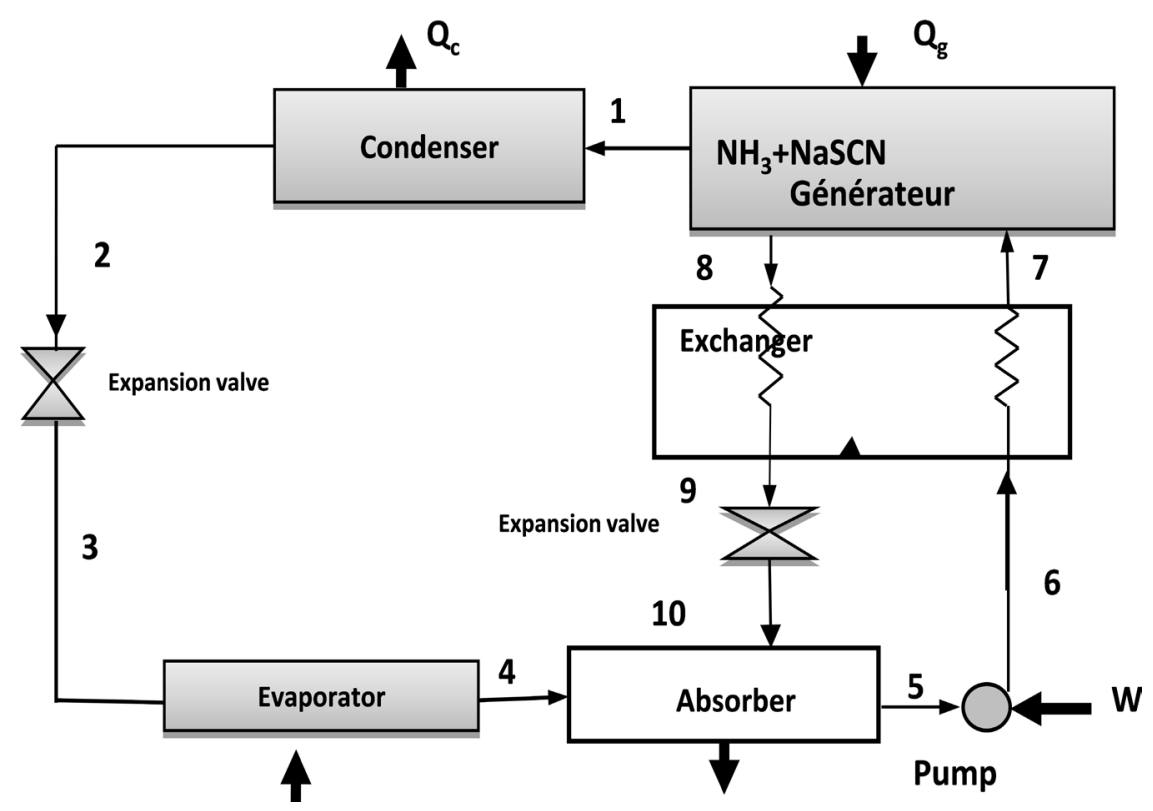

Figure 1. Single-effect absorption scheme (1). 


\subsection{Configuration Modelling}

Modelling is the mathematical representation of a part of the truth of a system. In this part, we will apply, the laws of thermodynamics, for the analysis of the system. The main equations are the following:

\subsubsection{Conservation of Chemical Mass and Species}

$$
\begin{aligned}
\sum \dot{m}_{e} & =\sum \dot{m}_{s} \\
\sum \dot{m}_{e} X_{e} & =\sum \dot{m}_{s} X_{s}
\end{aligned}
$$

\subsubsection{Energy Conservation}

$$
\sum \dot{m}_{e} h_{e}-\sum \dot{m}_{s} h_{s}+\sum\left(\dot{Q}_{e}-\dot{Q}_{s}\right)+W=0
$$

\subsubsection{Fluid Properties}

\section{Refrigerant $\mathrm{NH}_{3}$}

The relationship between pressure and temperature of ammonia in the two phases is $[10]$ :

$$
P(T)=10^{3} \sum_{i=0}^{6} a_{i}(T-273.15)^{i}
$$

The relationship between the enthalpy and temperature of the ammonia-saturated liquid is:

$$
h_{l}(T)=10^{3} \sum_{i=0}^{6} b_{i}(T-273.15)^{i}
$$

The relationship between the enthalpy and temperature of ammonia-saturated steam is:

$$
h_{v}(T)=10^{3} \sum_{i=0}^{6} b_{i}(T-273.15)^{i}
$$

The coefficients $a, b$ and $c$ are shown in Table 1 below.

Table 1. Polynomial coefficients of Equations (4)-(6).

\begin{tabular}{cccc}
\hline$i$ & $a_{i}$ Equation (4) & $b_{i}$ Equation (5) & $c_{i}$ Equation (6) \\
\hline 0 & $4.2871 \mathrm{e}^{-1}$ & $1.9879 \mathrm{e}^{2}$ & $1.4633 \mathrm{e}^{3}$ \\
1 & $1.6001 \mathrm{e}^{-2}$ & $4.4644 \mathrm{e}^{0}$ & $1.2839 \mathrm{e}^{0}$ \\
2 & $2.3652 \mathrm{e}^{-4}$ & $6.2790 \mathrm{e}-3$ & $-1.1501 \mathrm{e}^{-2}$ \\
3 & $1.6132 \mathrm{e}^{-6}$ & $1.4591 \mathrm{e}^{-4}$ & $-2.1523 \mathrm{e}^{-4}$ \\
4 & $2.4303 \mathrm{e}^{-9}$ & $-1.5262 \mathrm{e}^{-6}$ & $1.9055 \mathrm{e}^{-6}$ \\
5 & $-1.2494 \mathrm{e}^{-13}$ & $-1.8069 \mathrm{e}^{-8}$ & $2.5608 \mathrm{e}^{-8}$ \\
6 & $1.2741 \mathrm{e}^{-13}$ & $-1.9054 \mathrm{e}^{-10}$ & $-2.5964 \mathrm{e}^{-10}$ \\
Standard Error & $1.6 \mathrm{e}^{-3}$ & $8.5626 \mathrm{e}^{0}$ & $1.059 \mathrm{e}^{1}$ \\
Average deviation & $1.252 \mathrm{e}^{-2}$ & $5.566 \mathrm{e}^{-3}$ & $3.679 \mathrm{e}^{-3}$ \\
\hline
\end{tabular}




\section{The solution of $\mathrm{NH}_{3}-\mathrm{N}_{\mathrm{a}} \mathrm{SCN}$}

The relationship between saturation pressure and temperature of the $\mathrm{NH}_{3}-\mathrm{NaSCN}$ solution is given by formula [10]:

$$
\begin{gathered}
\ln P=A+\frac{B}{T} \\
A=15.7266-0.298628 X \\
B=-2548.6-2621.92(1-X)^{3}
\end{gathered}
$$

The relationship between enthalpy, temperature, and mass concentration is given by [10].

$$
\begin{gathered}
H=A+B(T-273.15)+C(T-273.15)^{2}+D(T-273.15)^{3} \\
A=79.72-1072 X+1287.9 X^{2}-3.5137 X^{3} \\
B=2.4081-2.2814 X+7.9291 X^{2}-3.5137 X^{3} \\
C=10^{-2}\left(1.255 X-3 X^{2}+3.06 X^{3}\right) \\
D=10^{-5}\left(-3.33 X+10 X^{2}-3.33 X^{3}\right)
\end{gathered}
$$

The density is given by the relation

$$
\begin{gathered}
\rho=A+B(T-273.15)+C(T-273.15)^{2} \\
A=1707.519-2400.4248 X+2256.5083 X^{2}-930.063 X^{3} \\
B=3.6341 X+5.4552 X^{2}-3.164 X^{3} \\
C=10^{-3}\left(5.1 X-3.6 X^{2}+5.4 X^{3}\right)
\end{gathered}
$$

The analysis of the performances by the first law is characterized by, the coefficient of performance:

$$
\mathrm{COP}=\frac{\dot{Q}_{E}}{\dot{Q}_{G}+W}
$$

The performance, using the second law is characterized by, the exergy efficiency:

$$
\mathrm{ECOP}=\frac{\dot{Q}_{E}\left(1-\frac{T_{0}}{T_{E}}\right)}{\dot{Q}_{G}\left(1-\frac{T_{0}}{T_{G}}\right)+W}
$$

\subsubsection{Hypotheses}

The analysis is based on the following assumptions:

- Heat losses of the system components are negligible.

- The solutions leaving the absorber and the generator are assumed to be saturated under the respective conditions of temperature and concentration.

- The refrigerant in the condenser and evaporator is saturated.

- Ammonia vapour from the generator is assumed to be superheated. 


\section{Results and Discussion}

A program has been developed using the Matlab software to solve the equations of this single-effect system, in order to analyse its performance. The thermodynamic properties of the $\mathrm{NH}_{3} / \mathrm{NaSCN}$ torque were also calculated from their polynomial equations.

\subsection{Variation of Specific Enthalpy}

Figure 2 below, shows the evolution of the specific enthalpy. It can be seen that the specific enthalpy increases with the generator temperature. This is a partial result of the global model to be validated.

\subsection{Validation of the Model}

The results obtained with numerical simulation under matlab, were compared with those already obtained by Sun [2].

These results are validated by making a comparison in Table 2 below.

A graphic comparison is made from the code, representing the COP of the current model, with reference COP (Figure 3).

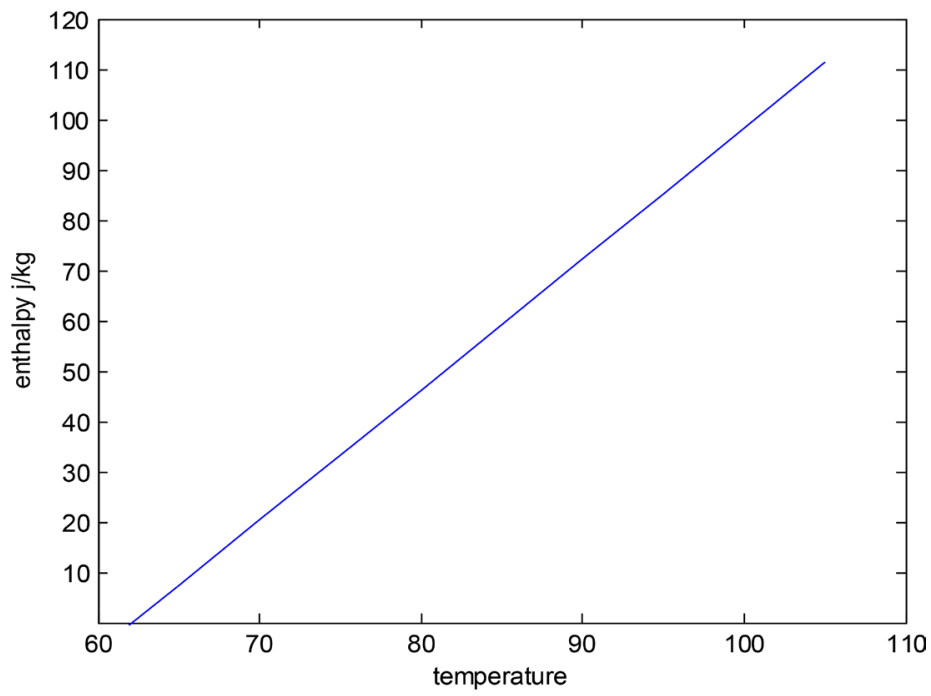

Figure 2. Specific enthalpy according to TG.

Table 2. Validation of numerical results.

\begin{tabular}{cccc}
\hline Thermal powers & Simulation results & Simulation results according to Sun & Error \\
\hline generator & $29.0302 \mathrm{~kW}$ & $29.0292 \mathrm{~kW}$ & 0.003 \\
Condenser & $18.4048 \mathrm{~kW}$ & $18.4611 \mathrm{~kW}$ & 0.305 \\
Evaporator & $18.5408 \mathrm{~kW}$ & $18.5974 \mathrm{~kW}$ & 0.304 \\
Absorber & $29.1661 \mathrm{~kW}$ & $29.2425 \mathrm{~kW}$ & 0.260 \\
Pump & $0.0769 \mathrm{~kW}$ & $0.0770 \mathrm{~kW}$ & 0.129 \\
Heat exchanger & $11.2093 \mathrm{~kW}$ & $11.2151 \mathrm{~kW}$ & 0.052 \\
COP & 0.6370 & 0.6390 & 0.313 \\
\hline
\end{tabular}




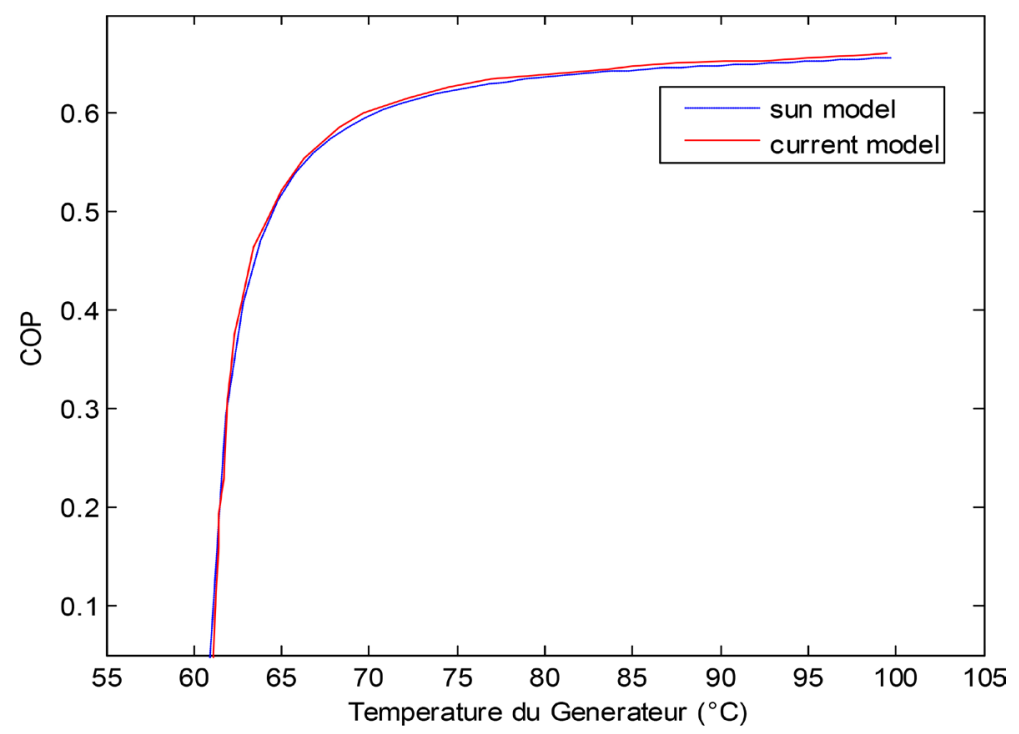

Figure 3. Validation of the COP according to TG.

\subsection{Validation of the Model of the Single-Effect System}

Given that the model is valid, input data are used to analyze the performance system.

$$
\begin{aligned}
& \mathrm{TG}=110^{\circ} \mathrm{C} \text {, generator's temperature; } \\
& \mathrm{TC}=30^{\circ} \mathrm{C} \text {, condenser's temperature; } \\
& \mathrm{TA}=25^{\circ} \mathrm{C} \text {, absorber's temperature; } \\
& \mathrm{TE}=-7^{\circ} \mathrm{C} \text {, condenser's temperature; } \\
& \text { eff }=0.8, \text { heat exchanger's efficiency; } \\
& \mathrm{m} 7=4.8 \mathrm{~kg} / \mathrm{s} \text {, mass flow rate at point } 7 .
\end{aligned}
$$

\subsection{System's Coefficient of Performance}

We can notice that the COP initially increases with increase in generator's temperature, and tends to stabilize rather than continue to increase; and with a further increase in generator's temperature, it reaches a final value of 0.7 (Figure 4). This increase in the generator's temperature causes an increase in the temperature of the refrigerant fluid, as well as that of the solution, leaving the generator to the absorber. Thus there is an increase in the average temperature of the condenser and the absorber, which explains the irreversible increase in these components. This justifies the positive effect of the increase in COP due to the increase in generator temperature is compensated by the degradation of the COP due to the increase in condenser and absorber temperatures. As a result, the heat level of the generator stops and the COP curve becomes almost constant, showing a marginal decrease in the COP.

\subsection{Single-Effect System Circulation Ratio}

As indicated in Figure 5, the circulation factor is also a vital element in the study of the performance of a system. An increase in generator's temperature leads to a 
decrease in the circulation rate. Thus for a constant cooling load, the reduction in the heat rate of the generator leads to an initial increase in the COP. At higher generator temperatures, the reduction rate of the solution circulation rate decreases, but the temperature difference between the generator and the solution increases, resulting in a decrease in the irreversibility of the generator.

\subsection{Energy Efficiency of the Single-Effect System}

Figure 6 shows that, as the generator temperature rises, the energy efficiency of the system first increases considerably to its maximum value 0.43 corresponding to the temperature of $79^{\circ} \mathrm{C}$, and then decreases continuously in order to reach its limit value 0.35 , as the generator's temperature rises afin d'atteindre sa valeur limite 0.35 . Such a behaviour can justify the variations in the COP's curve, as discussed previously, since the positive effect of the ECOP is compensated by the degradation of the ECOP, due to the increased temperatures of the condenser and the absorber.

\subsection{Coefficient of Performance and Energy Efficiency}

As indicated in Figure 7, for generator temperatures between $78^{\circ} \mathrm{C}$ and $90^{\circ} \mathrm{C}$, the coefficient of performance and energy efficiency have the best values for suitable functioning of the system. Above temperatures beyong $105^{\circ} \mathrm{C}$, the coefficient of performance increases towards its final value, while the energy efficiency continues to decrease. This results in the system having more energy losses for temperatures above $90^{\circ} \mathrm{C}$. Such losses are caused by the temperature difference between the absorber and the environment, the temperature difference between the source and the refrigerant, and the temperature difference between the evaporation temperature and the environment. So, we can choose generator temperatures in the range of $79^{\circ} \mathrm{C}$ and $90^{\circ} \mathrm{C}$, to maintain a more acceptable operation.

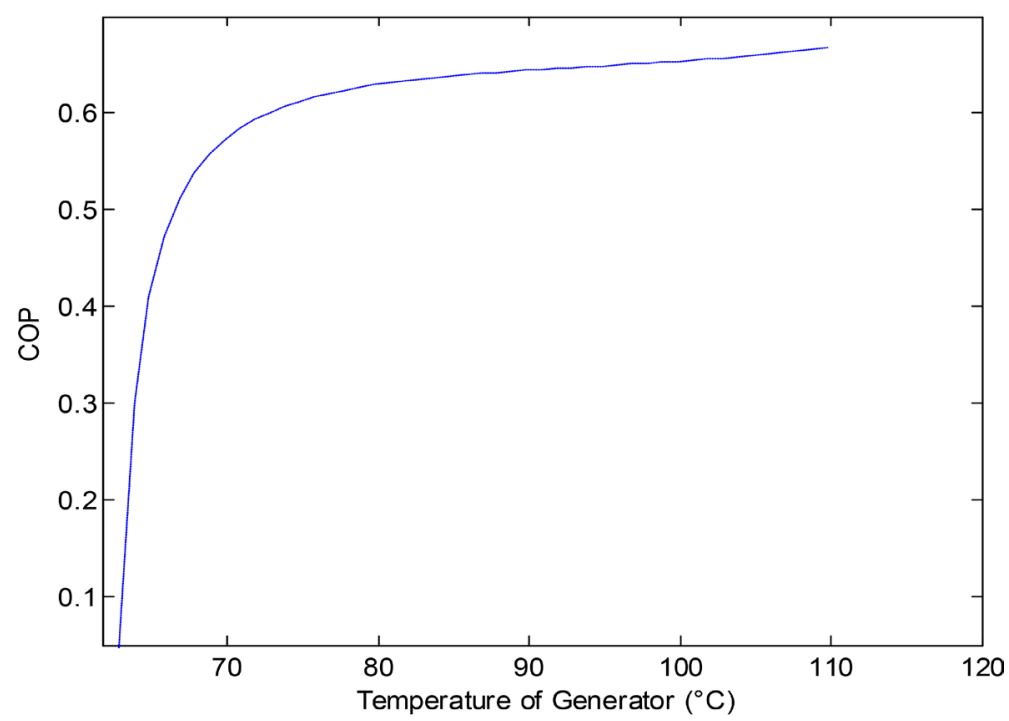

Figure 4. Variation of the COP according to TG. 


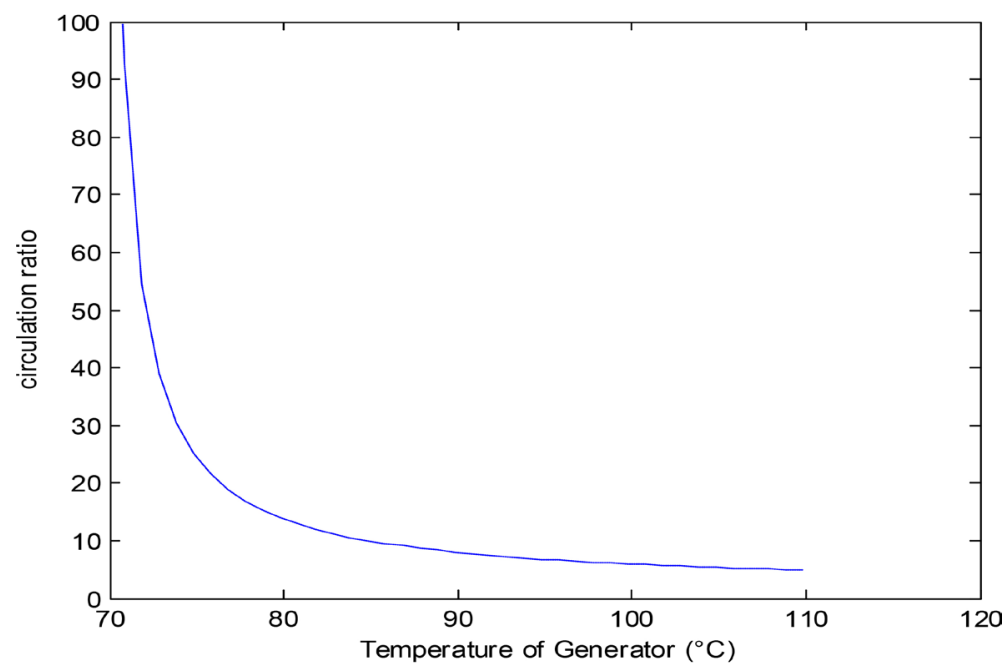

Figure 5. Variation of circulation factor with generator's temperature.

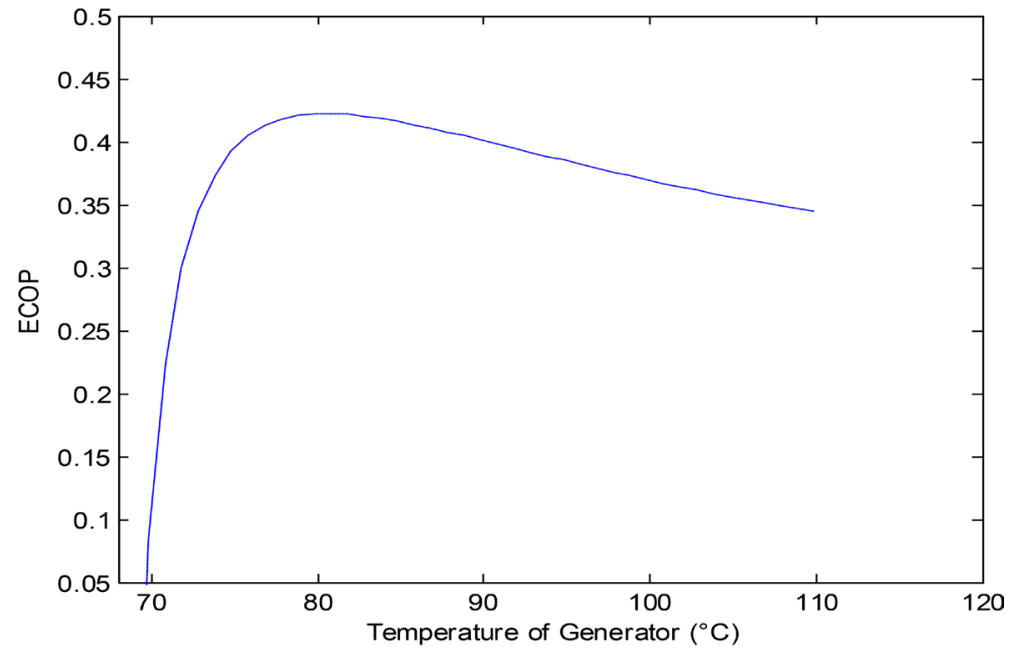

Figure 6. Variation of the energy efficiency according to the generator's temperature.

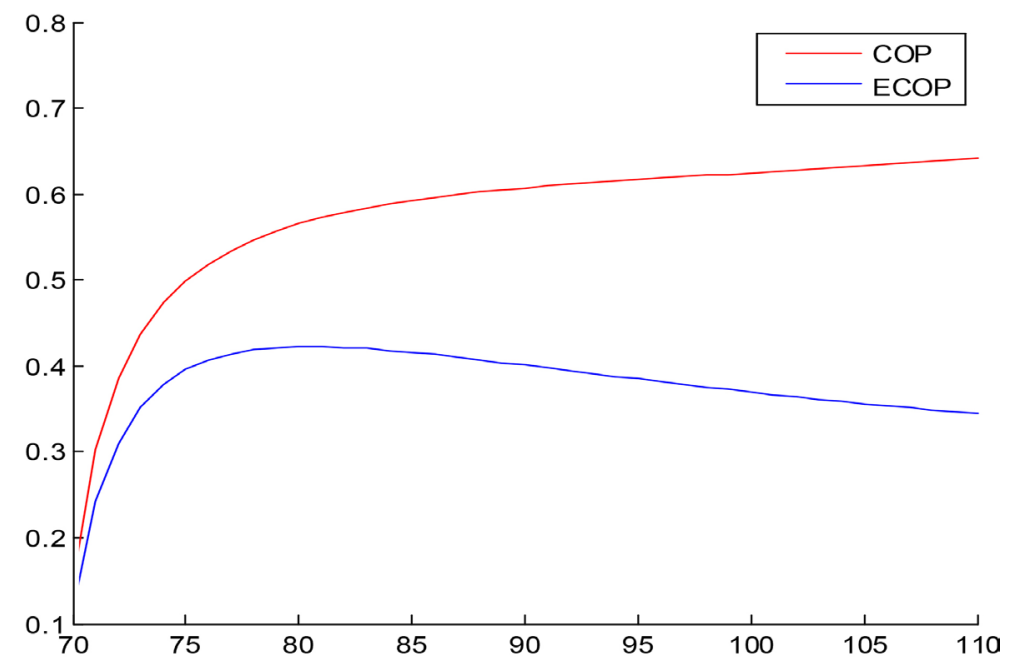

Figure 7. Simultaneous variation of the ECOP COP aiming at finding the optimal generator's temperature. 


\section{Conclusion}

A computer program has been developed to predict the performance of a single-effect absorption refrigeration system. Obtained results show the influence of the generator's temperature on the system performance. It is obvious that the generator's temperature is not the only parameter influencing the coefficient of performance and the efficiency of the system. In fact, there are other parameters that can strongly influence the performance of the machine, such as the temperature of the evaporator, the condenser and the absorber. This work, was limited to the effect of the generator's temperature because we have assumed that this is the starting point for system operation.

\section{Conflicts of Interest}

The authors declare no conflicts of interest regarding the publication of this paper.

\section{References}

[1] Cengel, Y.A. and Boles, M.A. (2008) Thermodynamique: Une approche pragmatique. Traduction et adaptation de Marcel Lacroix. Cheneliere McGraw-Hill, Montreal.

[2] Sun, D.W. (1998) Comparaison of Performances of $\mathrm{NH}_{3}-\mathrm{H}_{2} \mathrm{O}, \mathrm{NH}_{3}-\mathrm{LiNO}_{3}, \mathrm{NH}_{3}-\mathrm{NaSCN}$ Absorption Refrigeration Systems. Energy Conversion and Management, 39, 357-368. https://doi.org/10.1016/S0196-8904(97)00027-7

[3] Talbi, M.M. and Agnew, B. (2000) Exergy Analysis: An Absorption Refrigerator Using Lithium Bromide and Water as the Working Fluids. Applied Thermal Engineering, 20, 619-630. https://doi.org/10.1016/S1359-4311(99)00052-6

[4] Zhu, L.H. and Gu, J.J. (2010) Second Law-Based Thermodynamic Analysis of Ammonia/Sodium Thiocyanate Absorption System. Renewable Energy, 35, 1940-1946. https://doi.org/10.1016/j.renene.2010.01.022

[5] Ceroso, J., Best, R. and Romero, R.J. (2011) A Study of a Bubble Absorber Using a Plate Exchanger with $\mathrm{NH}_{3}-\mathrm{H}_{2} \mathrm{O}, \mathrm{NH}_{3}-\mathrm{LiNO}_{3}$ and $\mathrm{NH}_{3}-\mathrm{NaSCN}$. Applied Thermal Engineering, 31, 1869-1876. https://doi.org/10.1016/j.applthermaleng.2011.02.032

[6] Acuna, A., Velaquez, N. and Cereso, J. (2013) Energy Analysis of a Diffusion Absorption Cooling System Using Lithium Ammonia, Sodium Thiocyanate and Water as Absorbent Substances and Ammonia as the Refrigerant. Applied Thermal Engineering, 51, 1273-1281. https://doi.org/10.1016/j.applthermaleng.2012.10.046

[7] Gong, S.Y. and Boulama, K.G. (2014) Parametric Study of an Absorption Refrigeration Machine Using Advanced Exergy Analysis. Energy, 76, 453-467. https://doi.org/10.1016/j.energy.2014.08.038

[8] Xu, Y.J., Jiang, N., Wang, Q. and Chen, G.M. (2016) Comparative Study on the Energy Performance of Two Different Absorption-Compression Refrigeration Cycles Driven by Low-Grade Heat. Applied Thermal Engineering, 106, 33-41. https://doi.org/10.1016/j.applthermaleng.2016.05.169

[9] Cai, D.H., Jiang, J.K., He, G.G., Li, K.Q., Niu, L.J. and Xiao, R.X. (2016) Expérimental Evaluation on Thermal Performance of an Air-Cooled Absorption Refrigeration Cycle with $\mathrm{NH}_{3}-\mathrm{LiNO}_{3}$ and $\mathrm{NH}_{3}-\mathrm{NaSCN}$ Refrigerant Solutions. Energy Conversion and Management, 120, 32-43. https://doi.org/10.1016/j.enconman.2016.04.089

[10] ASHRAE (1993) ASHRAE 1791 Tullie Circle, NE, Atlanta, GA 30329. ASHRAE Handbook, Fundamentals. Chapter 17, 17.45, 17.81. 


\section{Names}

\section{Symbols:}

\section{Latin letters:}

$\dot{m} \quad$ Mass flow rate, $\mathrm{kg} / \mathrm{s}$

$\mathrm{x} \quad$ Concentration $\mathrm{NH}_{3}$ liquid, $\mathrm{kg} \mathrm{NH}_{3} / \mathrm{kg}$ solution

$\dot{Q} \quad$ Transferred power, kw

h Specific enthalpy, kj/kg

w Mechanical power, $\mathrm{W}$

$\mathrm{P} \quad$ Absolute pressure, $\mathrm{kPa}$

$\mathrm{T} \quad$ Temperature, $\mathrm{K}$

COP Coefficient of performance

ECOP Exercise efficiency

eff Heat exchanger efficiency

\section{Greek letters:}

$\rho \quad$ Density, $\mathrm{kg} / \mathrm{m}^{-3}$

\section{Hints/Exhibitors:}

e Entrant

s Outgoing

1 Liquid

v Steam

i Exhibitor

E Evaporator

G Generator

A Absorber

C Condenser

0 Absolute 